with newly diagnosed myeloma without intent for immediate autologous stem-cell transplant (SWOG S0777): a randomised, open-label, phase 3 trial. Lancet. 2017;389:519.

4. Ann E Engebretson. Comparable Outcomes With Bortezomib-Cyclophosphamide-Dexamethasone (VCD) and Bortezomib-LenalidomideDexamethasone (VRD) For Initial Treatment Of Newly Diagnosed Multiple Myeloma (MM). Blood. 2013;122(21):3178-3184.

5. Philippe Moreau, Cyrille Hulin, Margaret Macro et al. VTD is superior to VCD prior to intensive therapy in multiple myeloma: results of the prospective IFM2013-04 trial. Blood. 2016:2569-2574
6. Kyle RA, Gertz MA, Witzig TE et al. Review of 1027 patients with newly diagnosed multiple myeloma. Mayo Clin Proc. 2003:21.

7. Shaji Kumar. Randomized, multicenter, phase 2 study (EVOLUTION) of combinations of bortezomib, dexamethasone, cyclophosphamide, and lenalidomide in previously untreated multiple myeloma. Blood. 2012;119(19):4375-4382.

8. Katarina Uttervall, Johanna Borg Bruchfeld, Charlotte Gran et al. Upfront bortezomib, lenalidomide, and dexamethasone compared to bortezomib, cyclophosphamide, and dexamethasone in multiple myeloma. Eur J Haematol. 2019:247-254.

\title{
THỰC TRANG CAI THỞ MÁY VÀ MộT SỐ YẾU TỐ LIÊN QUAN ĐẾN CAI THỞ MÁY KÉO DÀI TẠI KHOA HỒI SỨC TÍCH CỰC BỆNH VIỆN BẠCH MAI
}

\section{TÓM TẮT}

Mục tiêu: Nghiên cứu nhằm phân loai cai thở máy theo tiêu chí mới của hội nghị đồng thuận quốc tế diễn ra năm 2005 và đánh giá một số yếu tố liên quan đến cai thở máy kéo dài tại khoa hồi sức tích cực bệnh viên Bach Mai. Đối tượng và phương pháp nghiên cứu: 176 bệnh nhân điều trị tại khoa HSTC cân phải thở máy xâm nhập đã cai máy thở thành công được phân loại thành các nhóm cai máy đơn giản, cai máy khó và cai máy kéo dài. Một số yếu tố liên quan cai máy kéo dài và tiên lượng sau cai máy được xác định. Kết quả: Số lượng bệnh nhân theo các nhóm cai máy đơn giản, cai máy khó, cai máy kéo dài lần lượt là 106, 42, 28 tương ứng tỷ lệ 60\%, 24\%, 16\%. Ở bệnh nhân cai máy kéo dài tỷ lệ tử vong hoăc năng xin về $11 \%$, tỷ lệ viêm phổi liên quan đên thở máy $68 \%$ so với 2 nhóm còn lai tỷ lệ này là $3 \%$ và $18 \%$. Chỉ số thơ nhanh nông RSBI $\geq 98$ và $\mathrm{PaCO}_{2} \geq 43 \mathrm{mmHg}$ trong nghiệm pháp tư thở đâu tiên có giá trị tiên lượng độc lập cho cai máy kéo dài. Kết luận: Phân loại mới về cai máy cho thây cai máy kéo dài có liên quan với tăng tỷ lệ nặng xin về hoặc tử vong tại viện. Trong quần thể nghiên cứu, nồng độ CO2 trong máu tăng cao cuối nghiệm pháp tự thở dự đoán cai thở máy kéo dài. Các bác sĩ lâm sàng cần có những chiến lược nhằm cải thiện kết quả cai thở máy.

Tư khóa: Tăng $\mathrm{CO}_{2}$ máu, cai máy kéo dài, ICU, cai thở máy.

\section{SUMMARY \\ INCIDENCE OF WEANING FROM MECHANICAL VENTILATION AND SEVERAL}

\footnotetext{
*Đại hoc Y Hà Nôi

Chịu trách nhiệm chính: Trần Quốc Minh

Email: qcm1923@gmail.com

Ngày nhận bài: 25.10.2021

Ngày phản biên khoa họ: 20.12.2021

Ngày duyệt bài: 30.12 .2021
}

\author{
Trần Quốc Minh*, Lê Thị Diễm Tuyết*
}

\section{FACTORS ASSOCIATED WITH PROLONGED WEANING IN INTENSIVE CARE UNIT OF BACH MAI HOSPITAL}

Purpose: The objective of the present study was to determine the incidence of weaning according to the new categories 2005 and to assess some factors associated with prolonged weaning in ICU of Bach Mai hospital. Methods: 176 patients admitted to the intensive care unit (ICU) and requiring mechanical ventilation were successfully weaned and classified into simple, difficult and prolonged weaning. Factors associated with prolonged weaning and outcomes were determined. Results: The cumulative incidences of simple, difficult, and prolonged weaning were $106(60 \%), 42(24 \%)$ and 28 $(16 \%)$, respectively. Hospital mortality was increased in patients with prolonged (11\%) weaning in comparison with those with simple and difficult weaning (3\%). RSBI $\geq 98$ and $\mathrm{PaCO}_{2} \geq 43 \mathrm{mmHg}$ during the spontaneous breathing trial independently predicted prolonged weaning. Conclusions: The new weaning category prolonged weaning is associated with increased mortality in the ICU. For the overall population, hypercapnia at the end of spontaneous breathing predicts prolonged weaning, clinicians should implement measures aimed at improving weaning outcome.

Keywords: Hypercapnia, Prolonged weaning, ICU, weaning from mechanical ventilation.

\section{I. Đă̆T VẤN ĐỀ}

Cai thở máy là quá trình giảm dần sự hỗ trợ của máy thở, chiếm tới 40 - 50\% tổng thời gian thở máy.Thở máy kéo dài tăng nguy cơ bị các nhiễm khuẩn mắc phải trong bệnh viện, tăng thời gian phải nằm tại khoa Hồi sức và làm tăng chi phí chăm sóc y tế cũng như gánh nặng cho gia đình bệnh nhân và xã hội.

Một hội nghị đồng thuận quốc tế diễn ra năm 
2005 đã phân loại cai thở máy theo 3 mức độ, cai thở máy đơn giản, cai thở máy khó và cai thở máy kéo dài. Cai thở máy kéo dài chiếm tỷ lệ nhỏ trong quần thể cai thở máy $7-20 \%$ tùy nghiên cứu. Tỷ lệ tử vong tại viện giữa nhóm cai thở máy đơn giản và cai thở máy khó không có sự khác biệt từ và tỷ lệ này cao rõ rệt ở nhóm cai thở máy kéo dài.

Nghiên cứu này được thực hiện nhằm 2 mục tiêu: Mô tả thực trạng cai thơ máy tại khoa Hồi sức tích cực bệnh viện Bạch Mai và phân tích một số yếu tố liên quan đến cai thở máy kéo dài.

\section{II. ĐỐI TƯợNG VÀ PHƯƠNG PHÁP NGHIÊN CứU}

2.1. Đối tượng nghiên cứu: 176 bệnh nhân nhập viện có thời gian thở máy $\geq 48$ tiếng, cai máy thở thành công. Địa điểm thực hiện khoa Hồi sức tích cực bệnh viện Bạch Mai. Thời gian nghiên cứu: 1/2021-6/2021.

\subsection{Phương pháp nghiên cứu:}

2.2.1: Thiết kế nghiên cứu: mô tả cắt ngang.

2.2.2: Quy trình nghiên cứu: Bệnh nhân được tiến hành cai máy khi đủ các tiêu chí. Lâm sàng: giải quyết hoặc kiểm soát được nguyên nhân làm bệnh nhân thở máy, thân nhiệt $<38^{\circ}$ $\mathrm{C}, \mathrm{Hb} \geq 8 \mathrm{~g} / \mathrm{dl}, \mathrm{GCS} \geq 9$; ý thức cải thiện sau ngừng an thần, mạch 60 - 140 lần/phút, huyết áp tâm thu $90-160 \mathrm{mmHg}$, không dùng vận mạch hoặc vận mạch liều thấp. Hô hấp: $\mathrm{PaO} 2$ /FiO2 $\geq 150 \mathrm{mmHg}, \mathrm{PEEP} \leq 8 \mathrm{cmH} 2 \mathrm{O}, \mathrm{FiO} 2 \leq 40 \%$.

Phương thức cai thở máy cho bệnh nhân, nghiệm pháp tự thở: PS với mức hỗ trợ thấp 5-8 cmH20, CPAP với PEEP $5 \mathrm{cmH} 20$ hoặc T-Tube. Thời gian 30 phút, ghi lại các thông số dấu hiệu sinh tôn, khí máu trước và sau SBT.

Cai máy thở thành công: nếu bệnh nhân tự thở tốt (không xuất hiện các triệu chứng không thích ứng) và $\mathrm{SpO} 2>92 \%$ cho đến khi rút được ống NKQ trong lần thử nghiệm đầu tiên, không phải thở lại máy sau rút ống NKQ $\geq 48 \mathrm{~h}$.

Cai máy thở thất bại: nếu bệnh nhân xuất hiện một trong các triệu chứng không thích ứng trong khoảng thời gian này. Tim mạch: Nhịp tim $\geq 140$ lần/phút hoặc tăng $\geq 20 \%$ so với mức nền. Huyết áp tâm thu $<90 \mathrm{mmHg}$ hoặc > $180 \mathrm{mmHg}$, tăng hoặc giảm $\geq 20 \%$ so với huyết áp nền. Hô hấp: Nhịp thở> 35 lần/phút hoặc tăng $\geq 50 \%$ so với nhịp thở trước đó, co kéo cơ hô hấp, thở nghịch thường, $\mathrm{SaO} 2<90 \%$ hoặc $\mathrm{PaO} 2<60 \mathrm{mmHg}$ với $\mathrm{FiO} 2 \geq 40 \%$. Thần kinh : Ý thức xấu hơn.

Cai máy đơn giản: Bỏ máy thở thành công và rút ống NKQ ngay lần đâu tiên sau 1 liệu pháp SBT. Cai máy khó: Cần phải làm SBT 2-3 lần mới bỏ được máy, hoặc thở máy và rút ống NKQ $\leq 7$ ngày kể từ khi làm thử nghiệm SBT lần đầu. Cai máy kéo dài: Thành công bỏ máy, rút ống NKQ $>3$ thử nghiệm SBT hoặc thở máy $>7$ ngày kể từ khi lầm thử nghiệm SBT lần đầu tiên.

2.2.3. Phân tích số liệu và xử lý số liệu: số liệu được phân tích theo phương pháp thổng kê y học, xử lý số liệu bằng phần mềm SPSS 20.0.

\section{KẾT QUẢ NGHIÊN CỨU}

3.1. Phân loại cai thở máy và đặc điểm giữa các nhóm. Nghiên cứu thực hiện trên 176 bệnh nhân có độ tuổi trung bình là $54.8 \pm 18.9$, bệnh nhân có tuổi thấp nhất là 15 và cao nhất là 102. Nam giới chiếm $62.5 \%$ (110), nữ giới $37.5 \%$ (66). Về nguyên nhân phải thở máy: bệnh hô hấp $34.7 \%$ (61), tim mạch $13.6 \%$ (24), sốc (ngoài bệnh lý phổi và tim) $18.2 \%$ (32), thân kinh trung ương $11.4 \%$ (20), thần kinh cơ 14.2\% (25), ngoại khoa 8\% (14). Số lượng bệnh nhân phân loại theo 3 nhóm cai máy đơn giản, khó, kéo dài lần lượt là 106, 42, 28, chiếm tỷ lệ tương ứng $60 \%, 24 \%$ và $16 \%$.

Bảng 1. Đặc điểm chung, bệnh lý nền và nguyên nhân phải thở máy

\begin{tabular}{|c|c|c|c|c|}
\hline & Cai máy đơn giản & Cai máy khó & Cai máy kéo dài & p \\
\hline Tuối & $55.6 \pm 17.8$ & $55.7 \pm 20.2$ & $50.3 \pm 21.1$ & 0.388 \\
\hline Nam giới & $72(67.9 \%)$ & $20(47.6 \%)$ & $18(64.3 \%)$ & 0.069 \\
\hline \multicolumn{5}{|c|}{ Bệnh kèm theo } \\
\hline Tăng huyết áp & $31(29.2 \%)$ & $13(31 \%)$ & $7(25 \%)$ & 0.861 \\
\hline Đái tháo đường & $18(17 \%)$ & $7(16.7 \%)$ & $1(3.6 \%)$ & 0.401 \\
\hline COPD & $11(10.4 \%)$ & $10(23.8 \%)$ & $2(7.1 \%)$ & 0.055 \\
\hline Suy tim & $17(16 \%)$ & $9(21.4 \%)$ & $7(25 \%)$ & 0.49 \\
\hline Suy thận & $19(18 \%)$ & $8(19 \%)$ & $2(7.1 \%)$ & 0.344 \\
\hline Hút thuổc lá & $14(13.2 \%)$ & $4(9.5 \%)$ & $1(3.6 \%)$ & 0.328 \\
\hline \multicolumn{5}{|c|}{ Nguyên nhân phải thở máy } \\
\hline Bệnh hố hấp & $35(33 \%)$ & $19(45.2 \%)$ & $7(25 \%)$ & 0.187 \\
\hline Bệnh tim mạch & $19(17.9 \%)$ & $3(7.1 \%)$ & $2(7.1 \%)$ & 0.125 \\
\hline Sốc khác & $27(25.5 \%)$ & $5(11.9 \%)$ & $1(3.6 \%)$ & 0.234 \\
\hline
\end{tabular}




\begin{tabular}{|c|c|c|c|c|}
\hline Bệnh thần kinh TW & $13(12.3 \%)$ & $3(7.1 \%)$ & $4(14.3 \%)$ & 0.587 \\
\hline Bệnh thần kinh cơ & $2(1.9 \%)$ & $12(28.6 \%)$ & $11(39.3 \%)$ & $<0.01$ \\
\hline Ngoại khoa & $10(9.4 \%)$ & $0(0 \%)$ & $4(14.3 \%)$ & 0.065 \\
\hline
\end{tabular}

Nhận xét: Không có sự khác biệt tuối, giới tính, bệnh lý nền giữa 3 nhóm. Tỷ lệ bệnh lý thần kinh cơ là nguyên nhân phải thở máy ở nhóm cai máy kéo dài cao hơn rõ rệt so với 2 nhóm còn lại, $\mathrm{OR}$ 6.2 CI 95\% (2.4-15.8).

\subsection{Các yêu tố liên quan đến cai thở máy kéo dài}

Bảng 2. Đặc điểm số ngày điều trị, tỷ lệ viêm phổi thở máy, tử vong

\begin{tabular}{|c|c|c|c|}
\hline & Đơn giản và khó & Kéo dài & p \\
\hline Số ngày thở máy & $5.3 \pm 3.2$ & $16.8 \pm 11.1$ & $<0.001$ \\
\hline Ngày thở máy trước SBT & $3.9 \pm 2.8$ & $7.3 \pm 5.5$ & $<0.001$ \\
\hline Số ngày nằm ICU & $11.0 \pm 6.6$ & $27.8 \pm 12.5$ & $<0.001$ \\
\hline Số ngày nằm viện & $18.8 \pm 15.7$ & $50.4 \pm 63.8$ & $<0.001$ \\
\hline Viêm phối thở máy & $26(18 \%)$ & $19(68 \%)$ & $<0.0001$ \\
\hline Xin về, tữ vong tại viện & $5(3 \%)$ & $3(11 \%)$ & 0.116 \\
\hline
\end{tabular}

Nhận xét: Số ngày thở máy trung bình của nhóm cai máy kéo dài nhiều gấp khoảng 4 lần so với nhóm cai máy đơn giản và 2 lần so với nhóm cai máy khó. Nhóm bệnh nhân cai máy kéo dài chiếm tỷ lệ $16 \%$ có tổng thời gian thở máy chiếm $37.4 \%$ của cả 3 nhóm. Sổ ngày thở máy trước SBT đầu tiên của nhóm cai máy kéo dài cao hơn rõ rệt so với 2 nhóm còn lại. Số ngày nằm viện cũng như số ngày điều trị tại ICU đều cao hơn rõ rệt ở nhóm cai máy kéo dài. Tỷ lệ nặng xin về, tử vong của nhóm cai máy kéo dài là $11 \%$ cao hơn so với 2 nhóm còn lại. Tỷ lệ viêm phổi thở máy ở nhóm cai máy kéo dài $68 \%$ cao gấp gần 4 lần so với 2 nhóm còn lại.

Bảng 3. Đặc điểm lâm sàng trước và sau nghiệm pháp tự thở.

\begin{tabular}{|c|c|c|c|}
\hline & Đơn giản và khó & Kéo dài & $\mathbf{p}$ \\
\hline \multicolumn{4}{|c|}{ Trước nghiệm pháp tự thở } \\
\hline Tân số thở (lần/phút) & $17.2 \pm 3.4$ & $17.2 \pm 3.0$ & 0.963 \\
\hline Nhịp tim (lần/phút) & $94.2 \pm 15.0$ & $97.3 \pm 11.5$ & 0.306 \\
\hline Huyết áp tâm thu $\mathrm{mmHg}$ & $115.6 \pm 12.5$ & $117.9 \pm 11.5$ & 0.372 \\
\hline \multicolumn{4}{|c|}{ Sau nghiệm pháp SBT } \\
\hline Tần số thở (lần/phút) & $21.7 \pm 3.4$ & $24.9 \pm 4.3$ & $<0.001$ \\
\hline Nhịp tim (lần/phút) & $98.6 \pm 16.2$ & $110.6 \pm 16.9$ & $<0.001$ \\
\hline Huyết áp tâm thu $\mathrm{mmHg}$ & $118.7 \pm 14.3$ & $129.5 \pm 16.0$ & $<0.001$ \\
\hline RSBI & $70.8 \pm 20.7$ & $99.4 \pm 27.6$ & $<0.001$ \\
\hline \multicolumn{4}{|c|}{ Biến đối trước và sau nghiệm pháp SBT } \\
\hline Tần số thở (lần/phút) & $4.5 \pm 4.7$ & $7.7 \pm 5.8$ & 0.002 \\
\hline Nhịp tim (lần/phút) & $4.4 \pm 5.1$ & $13.4 \pm 11.7$ & $<0.001$ \\
\hline Huyết áp tâm thu $\mathrm{mmHg}$ & $3.1 \pm 7.6$ & $11.6 \pm 10.3$ & $<0.001$ \\
\hline
\end{tabular}

Nhận xét: Các chỉ số về dấu hiệu sinh tồn giữa 3 nhóm trước nghiệm pháp tự thở không cho thấy sự khác biệt. Giá trị trung bình chỉ số thở nhanh nông RSBI ở nhóm cai máy kéo dài cao hơn so với 2 nhóm còn lại. Sau nghiệm pháp tự thở giá trị trung bình tần số thở, nhịp tim, huyết áp tâm thu đều tăng lên ở cả 3 nhóm, nhưng tăng rõ rệt ở nhóm cai máy kéo dài sự khác biệt có ý nghĩa thống kê.

Bảng 4. Đặc điểm khí máu trước và sau nghiệm pháp tự thở.

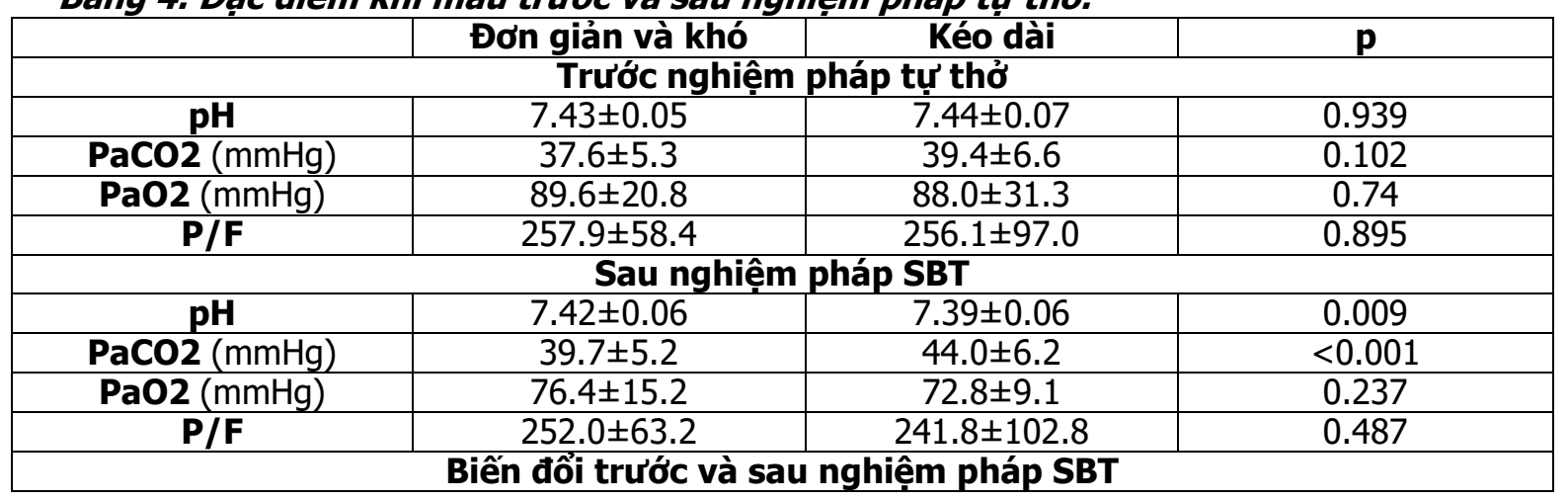




\begin{tabular}{|c|c|c|c|}
\hline pH & $0.01 \pm 0.04$ & $0.05 \pm 0.03$ & $<0.001$ \\
\hline PaC02 $(\mathrm{mmHg})$ & $2.2 \pm 3.3$ & $4.5 \pm 3.1$ & 0.001 \\
\hline
\end{tabular}

Nhận xét: Giá trị các chỉ số khí máu trước nghiệm pháp tự thở của 3 nhóm khá tương đồng. Sau nghiệm pháp tự thở, chỉ số PaO2, P/F giữa các nhóm không thay đổi nhiều. Chỉ số PaCO2 tăng lên

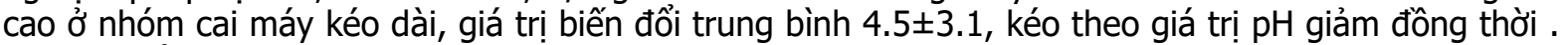
Sự biến đổi này không nhiều ở 2 nhóm còn lại.

Bảng 5. Các chi sốxét nghiệm máu và thang điểm đánh giá độ nặng.

\begin{tabular}{|c|c|c|c|}
\hline & Đơn giản và khó & Kéo dài & p \\
\hline Hgb $(\mathrm{g} / \mathrm{L})$ & $102.8 \pm 17.3$ & $108.2 \pm 13.6$ & 0.122 \\
\hline Albumin $(\mathrm{g} / \mathrm{L})$ & $30.1 \pm 3.2$ & $30.2 \pm 4.6$ & 0.848 \\
\hline Pre-albumin (mg/dL) & $0.17 \pm 0.04$ & $0.15 \pm 0.07$ & 0.051 \\
\hline Mg (mmol/L) & $0.7 \pm 0.09$ & $0.7 \pm 0.09$ & 0.348 \\
\hline SOFA & $5.3 \pm 2.6$ & $3.9 \pm 2.4$ & 0.008 \\
\hline SAPS II & $34.7 \pm 11.8$ & $32.7 \pm 15.4$ & 0.445 \\
\hline
\end{tabular}

Nhận xét: Bệnh nhân ở 3 nhóm đều cho thấy có mức độ thiếu máu nhẹ. Giá trị trung bình Prealbumin của cả 3 nhóm đều dưới ngưỡng bình thường (0.2-0.4), nhóm cai máy kéo dài có giá trị Prealbumin thấp hơn. Chỉ số Albumin, Mg cả 3 nhóm ở ngưỡng dưới của giá trị bình thường. Đây là tình trạng chung của những bệnh nhân phải thở máy nằm tại ICU dinh dưỡng không đây đủ. Điểm trung bình thang điểm đánh giá mức độ nặng suy tạng lúc vào SOFA ở nhóm cai máy kéo dài thấp hơn so với 2 nhóm còn lại. Điểm SAPS II trung bình không có sự khác biệt.

\section{Bảng 6. Các chỉ số giúp tiên lượng cai máy kéo dài}

\begin{tabular}{|c|c|c|c|c|c|}
\hline & AUC (95\%CI) & Điểm cắt & Độ nhạy & Độ đặc hiệu & p \\
\hline RSBI & 0.791 & 98 & 60 & 90 & $<0.001$ \\
\hline PaCO2 sau SBT & 0.705 & 43 & 67 & 75 & 0.001 \\
\hline Nhịp tim sau SBT & 0.698 & 108 & 61 & 71 & 0.001 \\
\hline Nhịp thở sau SBT & 0.712 & 26 & 46 & 85 & $<0.001$ \\
\hline Ngày thơ trước SBT & 0.786 & 4 & 89 & 62 & $<0.001$ \\
\hline
\end{tabular}

Nhân xét: Trong các chỉ số được khảo sát thì chỉ số thở nhanh nông RSBI có độ đặc hiệu tốt nhất $90 \%$, số ngày thở trước SBT có độ nhạy tốt nhất 89\%, diện tích dưới đường cong của 2 chỉ số này đạt giá trị lớn nhất. Giá trị $\mathrm{PaCO} 2 \geq 43$ sau thử nghiêm SBT tiên lượng cai máy kéo dài với độ nhạy 67\%, độ đặc hiệu 75\%.

\section{BÀN LUẬN}

4.1 Phân loại cai thở máy và đặc điểm giữa các nhóm. Nghiên cứu thực hiện trên 176 bệnh nhân có độ tuổi trung bình cao, chủ yếu là nam giới. Nguyên nhân chính phải thở máy là bệnh lý hô hấp 34.7\%. Tỷ lệ bệnh nhân theo phân loại 3 nhóm cai máy đơn giản, khó, kéo dài lần lượt là $60 \%, 24 \%$ và $16 \%$ gân giống với nghiên cứu của G-C. Funk ${ }^{[1]}$ trên quân thể 257 bệnh nhân ICU (tỷ lệ tương ứng 59\%, 26\%, $14 \%)$. Khác với nghiên cứu Jacobo Sellares ${ }^{[2]}$ trên quân thể bệnh nhân 181 bệnh nhân tại đơn vị hôi sức - hô hấp (tỷ lệ 43\%, 39\%, 18\%). Bệnh lý thân kinh cơ là nguyến nhân chủ yếu và cũ̃ng là yếu tố nguy cơ của cai máy kéo dài OR $6.2 \mathrm{CI}$ 95\% (2.4-15.8).

4.2 Các yếu tố liên quan đến cai thở máy kéo dài. Thời gian thở máy, thời gian điều trị tại khoa HSTC, nằm viện cao hơn ở nhóm cai máy kéo dài so với 2 nhóm còn lại $(p<0.01)$. Tỷ lệ viêm phổi liên quan máy thở cao gấp khoảng 4 lân so với 2 nhóm còn lại $(p<0.01)$. Tỷ lệ nặng xin về, tử vong tại viện của nhóm cai máy kéo dài $11 \%$ và của 2 nhóm còn lại là $3 \%$, nghiên cứu của G-C Funk ${ }^{[1]}$ thì tỷ lệ này tương ứng 22\% và $3 \%$. Tất cả nói lên gánh nặng y tế, nguồn lực cho bệnh nhân cai máy kéo dài lớn hơn rất nhiều so với nhóm còn lại.

Cai máy kéo dài chủ yếu là do mất cân bằng giữa nhu câu và khả năng tự thông khí của bệnh nhân biểu hiện yếu cơ hô hấp, thở nhanh nông, tăng $\mathrm{CO}_{2}$ trong máu khi thực hiện nghiệm pháp tự thở. Qua phân tích, chỉ sô RSBI, $\mathrm{PaCO}_{2}$, nhịp tim, nhịp thở sau nghiệm pháp tự thở có giá trị tiên lượng cai máy kéo dài. RSBI $\geq 98$ có độ nhạy $60 \%$, độ đặc hiệu 90\% (AUC 0.79, p<0.001), $\mathrm{PaCO}_{2} \geq 43 \mathrm{mmHg}$ sau nghiệm pháp tự thở có độ nhạy 67\%, độ đặc hiệu 85\% (AUC 0.7, $\mathrm{p}<0.001)$, theo nghiên cứu của Dooa $G$. Hassanin[3] thì giá trị $\mathrm{PaCO}_{2} \geq 49 \mathrm{mmHg}$ có độ nhạy $69 \%$, độ đặc hiệu $62 \%$, nghiên cứu của Jacobo Sellares[2] lại đưa ra giá trị $\mathrm{PaCO}_{2} \geq$ $54 \mathrm{mmHg}$ tiên lượng cai máy kéo dài.

\section{KẾT LUÂN}

Cai thở máy kéo dài có tiên lượng xấu so với 
nhóm cai thở máy đơn giản, và cai thở máy khó; đồng thời là gánh nặng cho chăm sóc lực y tế. Bệnh lý thần kinh cớ phải nhập viện thở máy là yếu tố nguy cơ cao cho cai thở máy kéo dài. RSBI và PaCO2 sau nghiệm pháp tự thở là yếu tố độc lập tiên lượng cho cai thở máy kéo dài.

\section{TÀI LIÊU THAM KHẢO}

1. Funk GC, Anders S, Breyer MK, Burghuber OC, Edelmann $\mathbf{G}$, Heindl $\mathbf{W}$, et al. Incidence and outcome of weaning from mechanical ventilation according to new categories. The European respiratory journal. 2010;35(1):88-94.

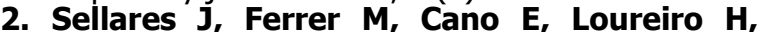
Valencia M, Torres A. Predictors of prolonged weaning and survival during ventilator weaning in a respiratory ICU. Intensive care medicine. 2011;37(5):775-84

3. Hamdy A. Mohammadien, Doaa G. Hassanin, Mona T. Hossien, Mostafa I. Ali. Predictors of prolonged weaning among mechanically ventilated patients in respiratory intensive care unit. Sohag medical journal. 2018; 22( 2):103-114

\title{
PHÂN TÍCH KẾT QUẢ LÂM SÀNG VÀ BIẾN CỐ BẤT LỢI TRÊN NGƯỜI BÊNH COVID-19 ĐƯợC SỬ DUNG THUỐC REMDESIVIR TẠI BÊ̂NH VIÊ̂N ĐA KHOA QUỐC TẾ VINMEC
}

\author{
Dương Thanh Hải ${ }^{1}$, Khổng Trọng Thắng ${ }^{2}$, Trương Ngọc Hải ${ }^{2}$, \\ Ngô Thị Thu Thủy ${ }^{2}$, Nguyễn Hoàng Phương Khanh ${ }^{2}$, Nguyễn Đỗ Quang Trung', \\ Lương Thị Hải Vân ${ }^{3}$, Nguyễn Lê Thùy Dung ${ }^{2}$, Lý Anh Thư ${ }^{2}$, \\ Bùi Hồng Ngọc ${ }^{2}$, Lê Quốc Sử ${ }^{2}$, Phan Quỳnh Lan ${ }^{1}$
}

\section{TÓM TẮT}

Remdesivir là thuốc kháng virus đã được chấp thuận trong điều trị bệnh nhân COVID-19 nhập viện ở nhiểu nước trên thế giới, trong đó có Viêt Nam. Tuy nhiên, hiện chưa có nghiên cứu nào về remdesivir được công bố tại Việt Nam. Chính vì thế, nghiên cứu được thực hiện để phân tích kết quả điều trị và độ an toàn của remdesivir trên bệnh nhân COVID-19 tai Viêt Nam. Nghiên cứu hồi cứu, mô tả thực hiện trên bệnh nhân COVID-19 từ 12 tuổi trở lên có chỉ định nhập viện và được điều trị với ít nhất một liêu remdesivir tử ngày 10/08/2021 đển ngày 10/09/2021 tại Bệnh viện đa khoa quốc tế Vinmec Central Park. Kết quả điều trị được đánh giá theo thang WHO 6 điểm, biến cố thở máy ngày 14 và tử vong tại thời điểm ngày 28 . Độ an toàn của remdesivir được đánh giá dựa trên tỷ lệ biến cố không mong muốn ghi nhận theo thang AIDS 2017.Kết quả: Nghiên cứu thu thập được 152 bệnh nhân COVID -19 được điêu trị bằng remdesivir, trong đó hơn $50 \%$ có ít nhất 1 bệnh lý nền, chủ yếu là bệnh lý tim mạch hoăcc đái tháo đường. Các bệnh nhân được dùng thuốc remdesivir trong vòng trung vị 6 ngày đâu khởi phát. Có $55,7 \%$ người bệnh cải thiện lâm sàng rõ rệt tại ngày thứ 11 so với trước khi dùng remdesivir. Chỉ có $14,6 \%$ bệnh nhân tiến triển nặng phải thở máy xâm nhập tính đến ngày thứ 14. Tỷ lệ tử vong ở ngày thứ 28 là 12,5\%. Các biến cố bất lợi được

${ }^{1}$ Bệnh viện đa khoa quốc tế Vinmec Times City

${ }^{2}$ Vinmec Central Park

${ }^{3}$ Vinmec Nha Trang

Chịu trách nhiệm chính: Phan Quỳnh Lan

Email: v.lanpq@vinmec.com

Ngày nhận bài: 18.10.2021

Ngày phản biên khoa học: 16.12.2021

Ngày duyệt bài: 24.12.2021 ghi nhận ở bệnh nhân dùng thuốc bao gồm tăng men gan $(29,6 \%)$, hạ kali $(26,3 \%)$, giảm độ lọc câu thận $(17,8 \%)$, chậm nhịp tim $(11,2 \%)$ và kéo dài thời gian prothrombin $(15,1 \%)$. Các yếu tố tiên lượng nặng lâm sàng bao gồm tuổi cao; mắc ít nhất một bệnh lý nền (COPD, tim mạch, đái tháo đường); người cần hỗ trợ thở oxy dòng cao HFNC, thở máy không xâm nhập hoặc thở máy xâm nhập;chỉ số ROX, tăng chỉ số viêm PCT, D-Dimer, ferritin; giảm số lượng bạch cầu lympho trước khi điều trị.

\section{SUMMARY}

\section{CLINICAL OUTCOMES AND SAFETY IN COVID -19 PATIENTS TREATED WITH REMDESIVIR IN VINMEC INTERNATIONAL HOSPITAL}

Remdesivir is an antiviral drug that has been approved for the treatment of hospitalized COVID-19 patients in many countries, including Vietnam. However, clinical data of remdesivir is lacking in Vietnam. This study was carried out to investigate clinical outcome and safety of remdesivir in the treatment of COVID-19 in Vietnam. A retrospective observational study was performed in all hospitalized COVID-19 patients 12 years of age and older treated with at least one dose of remdesivir from 10 August 2021 to 10 September 2021 at Vinmec Central Park Hospital. The clinical outcome was measured by the WHO 6-point scale, mechanical ventilation at day 14 , and 28-day mortality. The safety of remdesivir was evaluated based on the 2017 AIDS scale. Results: 152 patients were enrolled in this study with more than $50 \%$ had at least one comorbidity, mainly cardiovascular diseases or diabetes. Patients was treated with remdesivir at median 6 days after onset. $55.7 \%$ patients had significant clinical improvement at day 11 . In this study, $14.6 \%$ of patients received invasive mechanical ventilation on day 14 . The 28-day 